\title{
Idoso vítima de queimaduras: identificação do diagnóstico e proposta de intervenção de enfermagem
}

\author{
Aged victim of burns: identification of diagnosis and proposal of nursing interventions
}

Anciano con quemadura: identificación del diagnóstico y propuesta de intervención de enfermería

Maria Célia de Freitas

Doutora em Enfermagem Fundamental da Escola de Enfermagem de Ribeirão PretoUniversidade de São Paulo. Professora da Universidade Estadual do Ceará. maria.celia30@terra.com.br

Maria Manuela Rino Mendes

Professora Doutora da Escola de Enfermagem de Ribeirão Preto-Universidade de São Paulo.

\section{RESUMO}

Estudo de caso que objetivou identificar os Diagnósticos de Enfermagem (DE) conforme taxonomia II da Nursing American Nursing Association (NANDA), em idoso vítima de queimaduras de $2^{\circ}$ e $3^{\circ}$ graus e elaborar as intervenções de Enfermagem. Foram identificados oito DE, sendo cinco com presença de características definidoras e fatores relacionados (atuais) e três de risco. Elaborou-se propostas de intervenção iniciando pelas necessidades relacionadas aos sistemas vitais, fisiológicos, base da hierarquia das necessidades humanas básicas. Ao final, observou-se a importância da aplicabilidade do processo de enfermagem na implementação do cuidado e a necessidade do mesmo no exercício do fazer cotidiano.

Descritores: Queimaduras; Diagnóstico de Enfermagem; Cuidados de enfermagem.

\section{ABSTRACT}

This case study aimed at identifying the Nursing Diagnosis (ND) in agreement with the taxonomy II of the NorthAmerican Nursing Diagnosis Association (NANDA) of a patient victim of burning of $2^{\text {nd }} e 3^{\text {th }}$ degrees and to elaborate the nursing interventions. Eight ND were identified being five with the presence of defining characteristics and related factors (real), and three of risk. Intervention proposal was elaborated starting by the needs related to the vital and physiologic signs, the base of human basic needs hierarchy. Finally, it was observed the relevance of nursing process applicability in the implementation of care and its need in daily nursinga activitiies. Descriptors: Burns; Nursing Diagnosis; Nursing care.

\section{RESUMEN}

Estúdio de caso cuyo objetivo fué identificar los Diagnósticos de Enfermería (DE) según la taxonomia Il de North Ameircan Nursing Diagnosis Association (NANDA), de lo anciano com quemadura de $2^{\circ}$ e $3^{\circ}$ grado. Fueron identificados ocho DE de los más, cinco con presencia de características definidoras y factores relacionados (reales), y três de riesgos. Posteriomente, fueron elaboradas las porpuestas de intervención comenzado por la aplicabilidad del proceso de enfermería em la implementación del cuidado y la necessidad del mismo en el ejercício del hacer diário de enfermería.

Descriptores: Quemadura; Diagnóstico de enfermagem; Atención de enfermería.

Freitas MC, Mendes MMR. Idoso vítima de queimaduras: identificação do diagnóstico e proposta de intervenções de enfermagem. Rev Bras Enferm 2006 maio-jun; 59(3): 362-6.

\section{INTRODUÇÃO}

Pessoas vítimas de queimadura irão exigir assistência intensiva de enfermagem qualificada, pelas lesões e seqüelas decorrentes do evento. Em se tratando de pessoa idosa, cuja pele é atrófica, mais fina, desidratada e pouco vascularizada, sujeita às lesões mais profundas e de cicatrização mais lenta, com maior risco de infecção, constitui-se num desafio para o enfermeiro traçar planos de cuidados que atendam às inúmeras ameaças físicas que podem sobrevir, além dos aspectos social e psicológico.

Na velhice, ocorrem mudanças estruturais no sistema tegumentar caracterizadas pelo achatamento da articulação dermoepidérmica, variação no tamanho das células epiteliais, forma e corante das células basais, menores números de células e melanócitos, o que necessitará de vigilância contínua na tentativa de prevenir complicações decorrentes da queimadura ${ }^{(1)}$.

Queimadura, portanto, entendida como lesão dos tecidos orgânicos em decorrência de um trauma de origem térmica, elétrica, radioativo ou químico, sendo classificada em três graus: $1 .{ }^{\circ}$ grau: a lesão atinge apenas a epiderme, tendo como características, eritema e ardor na pele, sem formação de flictenas; $2 .^{\circ}$ grau: atinge a epiderme e parte da derme, caracterizada por ardor, eritema e presença de vesículas; $3 .^{\circ}$ grau: atinge a epiderme, derme e, às vezes, também o tecido subcutâneo, tendo como
Submissão: $21 / 10 / 2005$

Aprovação: 15/03/2006 
características, pele com aspecto esbranquiçado ou marmóreo, com redução da elasticidade tecidual, tornando-se rígida(2).

A fisiopatologia de uma queimadura pode ser expressa em quatro fases, que se sobrepõem, mas em geral indicam o choque neurogênico, o choque por perda de líquido, a infecção e degeneração do tecido queimado e a reparação.

A avaliação inicial do estado da queimadura se faz necessária para seleção do melhor método de tratamento, adotando roteiro para o manejo dos líquidos e definindo os recursos (equipe e materiais), disponíveis para o cuidado do idoso e providências cabíveis.

Ao avaliar o idoso vítima de queimaduras procura-se identificar a causa que determinou a lesão, descrever a condição geral, a extensão da área de superfície envolvida e a profundidade da queimadura. É importante certificar-se quanto ao local da ocorrência, se em área aberta ou fechada no momento do acidente, pois auxiliam a definir se existe comprometimento endotraqueal ou pulmonar real ou potencial.

Tal detalhamento objetiva identificar rapidamente a gravidade do caso, para planejar cuidados que possibilitem prevenir complicações e obter sucesso no tratamento.

E para orientar as intervenções, a partir das necessidades identificadas na avaliação, o enfermeiro utilizará os Diagnósticos de Enfermagem (DE), etapa do processo de enfermagem, para direcionar o planejamento das ações, acreditando ser a oportunidade de expressar os cuidados na abordagem integral, humana e individualizada, possibilitando excelência na prática profissional.

Ao trabalhar com o Processo de Enfermagem (PE) o enfermeiro compreenderá que este exige pensar a respeito de sua utilização no contexto do mundo atual em mudanças. Os enfermeiros são cada vez mais responsáveis por mostrar como seus cuidados conduzem resultados efetivos, planejados, com baixo custo. Esse benefício é obtido quando se utiliza o Processo de Enfermagem com identificação dos diagnósticos e com ele traçar propostas interventivas favorecedoras de avaliação contínua pela equipe.

Entende-se, por conseguinte, Diagnóstico de Enfermagem como o julgamento clínico sobre as respostas do indivíduo, família ou comunidade, aos problemas e processos da vida vigentes ou potenciais. Estes Diagnósticos de Enfermagem proporcionam a base para indicar as metas e intervenções de enfermagem visando obter resultados esperados como responsabilidade do enfermeiro ${ }^{(3,4)}$.

Dessa forma, compreende-se que utilizar o PE permite implementar uma prática cotidiana qualificada, em especial aos idosos, com resultados planejados e possibilidade de avaliação contínua do cuidado.

\section{OBJETIVOS}

- Identificar os DE em um idoso vítima de queimaduras de $2^{\circ}$ e $3^{\circ}$ graus, internado em uma instituição de referência no tratamento a pessoas queimadas

- Elaborar intervenções de enfermagem, relatando a implementação e avaliações realizadas no período de realização do estudo.

\section{METODOLOGIA}

Caracteriza-se o estudo como uma pesquisa do tipo estudo de caso. Optou-se por esta modalidade em virtude de proporcionar a compreensão ampla do sujeito pesquisado, ao mesmo tempo em que permite estabelecer posições mais gerais sobre a singularidade da dinâmica social(5).

Descrevem-se como características fundamentais de um caso, a saber ${ }^{(5)}$ :

- Visa à descoberta de novos elementos ou dimensões do problema com a progressão do estudo, por isso, não há exigências de pressupostos teóricos pré-fixados.

- Visa retratar a realidade de forma complexa e profunda, revelando a multiplicidade de dimensões de uma determinada situação.

- Utiliza várias fontes de informações: observações, reuniões, entrevistas, documentos, fotografias, obtidas em diferentes momentos que origina grande variedade de informações, que podem ser cruzadas para confirmar ou rejeitar hipóteses, descobrir novos dados e alternativas.

- Permite generalizações naturalísticas, que ocorrem em função da experiência do leitor, e associação com os dados encontrados no estudo.

- Mostra vários pontos de vista presentes numa situação social, pois não existe uma única perspectiva de ver a realidade que seja a mais verdadeira.

- O pesquisador pode deixar clara sua opinião quanto aos aspectos divergentes do estudo.

- Os dados escritos apresentam um estilo narrativo e informal, ilustrado com exemplos de citações pessoais e descrições.

Dessa forma, a opção pelo estudo de caso, ocorreu por possibilitar estar junto da situação a ser pesquisada e refletir com profundidade a realidade e as múltiplas dimensões existentes. Permite ainda, identificar os Diagnósticos de Enfermagem, planejar as intervenções contemplando os aspectos biopsicossociais, espirituais, da situação ou as necessidades humanas básicas.

Os dados foram coletados num hospital do município de Fortaleza$\mathrm{CE}$, que atende pessoas vítimas de queimaduras. Os meses de junho e julho de 2005, período de internação do idoso, foram utilizados para coletar dados. A escolha do idoso foi por conveniência, considerando as suas condições para responder ao inquérito sobre saúde e doença e estar cônscio para opinar sobre a aceitação de participar da pesquisa.

Para coleta de dados adotou-se, inicialmente, um roteiro sistematizado sobre a situação de saúde do idoso, que torna possível a identificação de seus problemas, necessidades psicobiológica, psicossocial e psicoespiritual. Dessa forma, tornava-se possível a identificação de suas respostas aos problemas e alterações da saúde, baseado nas necessidades ${ }^{(6)}$.

No primeiro contato com o idoso foram explicados os objetivos da proposta de estudo e como seria realizada. Após confirmação de aceite, foi iniciada a entrevista clínica e preenchimento do histórico, contendo informações subjetivas (anamnese) e objetivas (exame físico), além das observações.

O preenchimento do instrumento e avaliação física da condição do idoso levou em média 2 horas e 30 minutos. Após esse momento, realizouse consulta ao prontuário para reafirmar os dados coletados, por meio das evoluções e registros de enfermagem e médico, bem como os exames laboratoriais e imagens contidos no prontuário.

Concluída a coleta dos dados no histórico, fez-se o julgamento clínico dos dados, considerando os padrões de resposta humana (PRH), base para indicar os Diagnósticos de Enfermagem. Julgamento clínico entendido como a análise e decisões complexas do estado da pessoa, família e sua situação contextual, que afetam as respostas dessa pessoa ou família, baseada nos dados e conhecimentos para interpretação ${ }^{(7,8)}$.

Nessa análise (julgamento clínico e raciocínio diagnóstico), os dados foram agrupados em categorias, e necessidades que permitiram identificar a existência de lacunas e dados divergentes.

No caso do idoso, as respostas foram à situação de queimadura, considerando as condições próprias do processo de envelhecer com as alterações da pele, seguida das fisiológicas, que podiam comprometer sensivelmente a evolução, e resposta ao tratamento proposto para cada momento.

O estudo obedeceu aos preceitos estabelecidos na Resolução 196/ 96 que trata de Pesquisa com Seres Humanos. A proposta foi encaminhada e aprovada pelo Comitê de Ética da Universidade Estadual do Ceará, bem como se obteve a aquiescência da diretoria da instituição e dos gerentes médico e enfermeira, da unidade. Após esclarecimento da proposta do estudo tanto ao idoso quanto a filha que o acompanhava, diariamente, solicitou-se a assinatura do termo de consentimento livre e 


\section{IDENTIFICAÇÃO:}

CATEGORIZAÇÅO DOS DADOS

M.C.A, 71 anos, masculino, moreno, $2^{\circ}$ grau completo, motorista, 01 filha, residente no interior de São Paulo em casa de alvenaria com infra estrutura, 06 cômodos. Mora com a esposa e filha. Internado dia 2 de agosto de 2005 na unidade de queimados ( $1^{\circ}$ internação), com diagnóstico de queimadura do $2^{\circ}$ e $3^{\circ}$ graus no hemitórax e hemiabdome direito, lateral externa do antebraço, $1^{\circ}$ e $5^{\circ}$ quirodáctilo direito, face anterior da coxa direita e área interna do $1^{\circ}$ quirodáctilo esquerdo.

\section{EXPECTATIVAS E PERCEPÇÕES:}

$\mathrm{Na}$ entrevista de admissão estava com 24 horas de internação e 72 horas de acidente. Informou que foi socorrido e conduzido para um hospital local, onde foram prestados os primeiros atendimentos e depois transferido para esta Unidade Especializada. Diz que se manteve acordado e consciente durante todo 0 atendimento e que sentia muitas dores que eram aliviadas após medicação.

Fala, particularmente, sobre 0 acidente dizendo que espera retornar rapidamente as suas atividades e, mesmo sabendo que a queimadura deixará seqüelas, não se preocupa e diz "é estar vivo e voltar a trabalhar que me importo e logo".

Diz que tem esquema de vacinação anti-tetânica completo.

\section{NECESSIDADES BÁSICAS}

No momento refere dor, mas diz ser tolerável (fez uso de medicação há aproximadamente 1 hora). Em casa, alimenta-se no desjejum: leite, café e pão. No almoço arroz, feijão, carne e refrigerante. No jantar idem ao almoço. Comenta que faz alguns lanches nos intervalos das refeições.

No Hospital ingere alimentos hiperprotéicos e hipercalóricos, com complementos através de dietas especiais (proteínas e eletrólitos).

Informa que não tem qualquer atividade física extra ao trabalho.

Chora fácil, quando fala da filha, dizendo Ter saudades. Quando questionado sobre o repouso, ele falou que não consegue conciliar o sono na noite anterior a entrevista, por causa da posição no leito e dor tipo "queimação", nas áreas queimadas. Espera que as queimaduras não irão interferir na sua atividade sexual.

Pouco comunicativo e fica maior parte do tempo vendo televisão.

\section{EXAME FÍSICO}

Consciente, orientado, verbalizando com linguagem clara, objetiva. A preocupação com provável visita da filha e esposa, e com o dia em que sairá de alta, pra retornar ao trabalho.

Higiene geral e bucal, preservada; $P$ eso $=112 \mathrm{~kg}$; altura $=1,79 \mathrm{~m}$

$\mathrm{T}=37.6^{\circ} \mathrm{C}$ (axilar); P.A=140X90mmHg (MSE). FR=21mov. $/ \mathrm{min}$. Respiração rítmica, profunda e simétrica. FC= 105 bat. $/ \mathrm{min}$ (apical). $\mathrm{P}=103 \mathrm{pp} / \mathrm{min}$ (radial esquerdo). Pulso cheio e rítmico.

Tórax: mantido com curativo fechado. Renovado diariamente

Abdome distendido, sem dor à palpação. Curativo fechado

Musculatura dos membros preservada.

Presença de edema no membro superior direito e membros inferiores direito e esquerdo (3/4+).

Acamado, dependente de cuidados por apresentar curativos fechados na coxa $\mathrm{D}$ e pés e apresentar dificuldades para movimentar, no leito.

\section{Quadro 1. Categorização dos dados.}

esclarecido para ambos.

\section{RESULTADOS E DISCUSSÃO}

Os dados coletados na entrevista clínica, exame físico, assim como os obtidos pelas observações foram organizados e, posteriormente, realizada uma leitura criteriosa para verificar a necessidade de retorno ao idoso para preenchimento das lacunas, se existissem.

A seguir será apresentada a fase de elaboração com a categorização dos dados, segundo a proposta de Risner ${ }^{(9)}$, no quadro 1.

A síntese dos dados encontrados está disposta no quadro 2. A partir da síntese do julgamento clínico e pensamento crítico, componente essencial da responsabilidade profissional e da qualidade da assistência de Enfermagem ${ }^{(3)}$, foram identificados os Diagnósticos de Enfermagem que se seguem, fundamentados na North American Nursing Diagnosis Association (NANDA)|(10):

1) Risco para déficit de volume de líquido, relacionado às queimaduras de $2 .^{\circ}$ e $3 .^{\circ}$ graus em $12,5 \%$ da superfície corpórea.

2) Integridade da pele prejudicada, relacionada com fator físico (asfalto em alta temperatura), manifestada pela solução de continuidade da pele queimada e pelo ferimento com sutura na mandíbula.

3) Risco para alteração da temperatura corporal, relacionado às queimaduras em $12,5 \%$ da superfície corporal.

4) Risco para infecção, relacionado às lesões térmicas em $12,5 \%$ da superfície corporal.

5) Mobilidade física prejudicada, relacionada a obesidade, lesões térmicas, queimaduras, manifestada pela dificuldade para se movimentar e dor.

6) Estratégia ineficaz de resolução individual, relacionada à hospitalização, manifestada por episódios freqüentes de choro, preocupação com a família e trabalho.

7) Distúrbio do padrão do sono, relacionado às dores e dificuldades em assumir posição habitual devido às queimaduras, manifestado pelo incômodo ao decúbito dorsal.

8) Dor, relacionada a queimadura em $12,5 \%$ do corpo, manifestada por queixas verbais e expressão facial.

Após a identificação dos diagnósticos de enfermagem, foram planejadas as intervenções de maneira hierarquizada em subgrupos, bem como as metas e objetivos que atendessem as necessidades do idoso vítima de queimaduras do $2^{\circ}$ e $3^{\circ}$ graus. Tais intervenções estão ilustradas no quadro 3.

\section{Planejamento - Metas e Objetivos}

Os enfermeiros usam um processo de tomada de decisão para identificar inferências e determinar um diagnóstico de enfermagem. Selecionam as intervenções para atingir resultados almejados (Quadro 4).

Seguido esse momento, foram elaboradas as intervenções de enfermagem para os DE. Estas foram registrados em folhas apropriadas da unidade e solicitadas para que a equipe efetivasse as prescrições, segundo os horários estabelecidos, projetando resultados desejados.

As intervenções mais complexas do tipo; remoção das áreas com queimaduras, curativos, avaliação do processo de cicatrização, dentre outras, foram atividades realizadas em conjunto, equipe de enfermagem e médica. Tais atividades refletiam o compromisso do cuidado pelos profissionais, naquela unidade.

\section{Implementação e Avaliação das Intervenções Realizadas}

As prescrições foram implementadas obedecendo aos horários, previamente acordados e discutidos com a enfermeira responsável por cada plantão. Respeitava-se, ainda, a dinâmica do serviço. Aos demais componentes da equipe explicou-se a importância da colaboração e participação no processo de cuidar. Explicitava-se que os resultados possibilitariam cuidado com qualidade e recuperação do idoso atendendo aos anseios do trabalho interdisciplinar, enfatizando o compromisso da equipe de enfermagem.

$\mathrm{Na}$ implementação, colocação do plano em ação, incluiu: preparar para comunicar e receber comunicações; estabelecer as prioridades diárias; investigar e reinvestigar; realizar as intervenções e fazer as mudanças necessárias; registrar e fazer a comunicação(3). 


\begin{tabular}{|c|c|c|c|}
\hline AGRUPAMENTO & NECESSIDADES AFETADAS/COMPARAÇÃO & INFERÊNCIAS & RELAÇÃO \\
\hline $\begin{array}{l}\text { Queimadura no hemitórax e hemiabdome à direita; } \\
\text { Dor no local da queimadura; } \\
\text { FR: } 21 \mathrm{mrpm} \text {; } \\
24 \text { anos / sexo masc. }\end{array}$ & $\begin{array}{l}\text { Oxigenação / } \\
\text { - Sem queimaduras } \\
\text { - Sem dor } \\
\text { - FR: } 12 \text { - } 18 \text { mrpm }\end{array}$ & $\begin{array}{l}\text { Risco para padrão respiratório } \\
\text { ineficaz }\end{array}$ & Dor \\
\hline $\begin{array}{l}\text { Queimaduras de } 2 .^{\circ} \text { e } 3 .^{\circ} \text { graus em } 12,5 \% \text { da } \\
\text { superfície corpórea; } \\
\text { Edema em MSD e MMII (2/4+); } \\
\text { FC=105mpm; } \\
\text { P.A=140x90mmhm }\end{array}$ & $\begin{array}{l}\text { Circulação / } \\
\text { - Pele íntegra } \\
\text { - Sem edema }\end{array}$ & $\begin{array}{l}\text { Risco para déficit de volume de } \\
\text { líquido. }\end{array}$ & Perda ativa de líquidos \\
\hline $\begin{array}{l}\mathrm{T}=37.6^{\circ} \mathrm{C} ; \\
\text { Queimaduras de } 2^{\circ} \text { e } 3^{\circ} \text { graus em } 12.5 \% \text { da } \\
\text { superfície corpórea }\end{array}$ & $\begin{array}{l}\text { Termorregulação / } \\
\text { - Temperatura entre } \\
36^{\circ} \text { a } 37,5^{\circ} \mathrm{C}\end{array}$ & $\begin{array}{l}\text { Risco para alteração da } \\
\text { temperatura corporal }\end{array}$ & Superfície corporal queimada \\
\hline $\begin{array}{l}P=112 \mathrm{~kg} \\
A=1,72 \mathrm{~m} \\
\text { sexo masculino; } 24 \text { anos; } \\
\text { ingere muito refrigerante; } \\
\text { não pratica atividade física regular }\end{array}$ & $\begin{array}{l}\text { Nutrição / } \\
\text { - Peso de acordo com a altura }\end{array}$ & $\begin{array}{l}\text { Nutrição alterada: ingestão } \\
\text { maior do que a necessidades } \\
\text { corporais }\end{array}$ & Obesidade \\
\hline $\begin{array}{l}\text { Dificuldade para se movimentar; } \\
\text { Dor; } \\
\text { P=112Kg; } \\
\text { Queimaduras em } 12,5 \% \text { do corpo }\end{array}$ & $\begin{array}{l}\text { Exercícios e atividades físicas / } \\
\text { - Movimentar-se sem dificuldades }\end{array}$ & Mobilidade física prejudicada & $\begin{array}{l}\text { Obesidade; } \\
\text { Queimaduras }\end{array}$ \\
\hline $\begin{array}{l}\text { Pele e mucosa hidratada }(3 / 4+) ; \\
\text { ferimento com sutura de }+/-10 \mathrm{~cm} \text { na região } \\
\text { esquerda da mandíbula; } \\
\text { Curativos oclusivos nas áreas queimadas } \\
\mathrm{T}=37 . \mathrm{C}\end{array}$ & $\begin{array}{l}\text { Integridade da pele / } \\
\text { - Pele íntegra } \\
\text { - Temperatura entre } \\
36^{\circ} \text { a } 37,5^{\circ} \mathrm{C}\end{array}$ & $\begin{array}{l}\text {-Integridade da pele } \\
\text { prejudicada. } \\
\text {-Risco para infecção }\end{array}$ & $\begin{array}{l}\text { Solução de } \begin{array}{l}\text { continuidade- } \\
\text { queimaduras em } 12,5 \% \text { da } \\
\text { superfície corporal }\end{array}\end{array}$ \\
\hline $\begin{array}{l}\text { Dificuldade para conciliar o sono; } \\
\text { Incômodo no decúbito dorsal; } \\
\text { Dor }\end{array}$ & $\begin{array}{l}\text { Sono e repouso/ } \\
\text { Sono e repouso tranqüilos nas oito horas de repouso } \\
\text { noturno }\end{array}$ & Distúrbio do padrão do sono & Dor \\
\hline $\begin{array}{l}\text { Choro fácil } \\
\text { Pouco comunicativo } \\
\text { Preocupado em voltar para o } \\
\text { convivio com familiares }\end{array}$ & $\begin{array}{l}\text { Segurançal } \\
\text { Eficiência para resolução dos problemas individuais }\end{array}$ & $\begin{array}{l}\text { Estratégia ineficaz } \\
\text { resolução individual }\end{array}$ & Distância da família \\
\hline Dor tipo "queimação". Ardor. Calor na pele. & $\begin{array}{l}\text { Percepção sensorial / } \\
\text { Ausência de dor }\end{array}$ & Dor & Lesão por excesso de calor \\
\hline
\end{tabular}

Quadro 2. Síntese dos dados.

\begin{tabular}{|c|c|c|}
\hline $\begin{array}{c}\text { NECESSIDADE AFETADA/ } \\
\text { INFERENCIA }\end{array}$ & META & OBJETIVO \\
\hline $\begin{array}{ll}\text { Circulação/ } & \text { Risco para déficit de } \\
\text { volume de líquidos } & \end{array}$ & $\begin{array}{l}\text { O paciente deverá estar prevenido quanto aos } \\
\text { riscos da hiper/hipovolemia }\end{array}$ & $\begin{array}{l}\text { Manter a ingestão e a eliminação adequadas; } \\
\text { Manter as mucosas úmidas; } \\
\text { Apresentar turgor frouxo }\end{array}$ \\
\hline $\begin{array}{l}\text { Termorregulação/ Risco para alteração } \\
\text { da temperatura corpórea }\end{array}$ & $\begin{array}{l}\text { O paciente deverá estar prevenido com relação às } \\
\text { oscilações de temperatura }\end{array}$ & Manter a temperatura corpórea dentro dos padrões de normalidade \\
\hline $\begin{array}{l}\text { Integridade da pele/ } \\
\text { 1)Integridade da pele prejudicada } \\
\text { 2)Risco para infecção }\end{array}$ & $\begin{array}{ll}\text { O paciente deverá: } & \text { 1)Ter restabelecida sua } \\
\text { integridade da pele } & \\
\text { 2)Ter prevenida a infecção } & \end{array}$ & $\begin{array}{l}\text { 1)Proporcionar condições para a cicatrização das queimaduras de } 2^{\circ} \mathrm{grau} \text {, } \\
\text { favorecendo o surgimento dos tecidos de granulação; } \\
\text { 2)Promover condições para a proteção da pele lesada }\end{array}$ \\
\hline $\begin{array}{l}\text { Sono e Repouso/ } \\
\text { Distúrbio do padrão do sono }\end{array}$ & $\begin{array}{l}\text { O paciente deverá ter restabelecido seu padrão do } \\
\text { sono }\end{array}$ & Proporcionar condições de repouso nas oito horas do período noturno \\
\hline $\begin{array}{l}\text { Exercicios e atividades físicas/ } \\
\text { Mobilidade fisica prejudicada }\end{array}$ & $\begin{array}{l}0 \text { paciente deverá ter restauradas as suas } \\
\text { atividades físicas }\end{array}$ & Favorecer movimentos livres em suas atividades diárias \\
\hline $\begin{array}{l}\text { Segurança/ } \\
\text { Estratégia ineficaz de resolução individual }\end{array}$ & $\begin{array}{l}\text { O paciente deverá ter promovida às condições que } \\
\text { favoreçam } 0 \text { reajuste aos estressores da } \\
\text { hospitalização }\end{array}$ & Atenuar a saudade da filha e familiares \\
\hline $\begin{array}{l}\text { Percepção sensorial/ } \\
\text { Dor }\end{array}$ & O paciente deverá ter prevenida a dor & Avaliar e atenuar os agentes causadores da dor \\
\hline
\end{tabular}

Quadro 3. Intervenções de enfermagem.

A avaliação das intervenções foi realizada a cada 24 ou horas juntamente com a equipe. No entanto, os diagnósticos eram confirmados ou não, diariamente, pela enfermeira da unidade, bem como outros poderiam ser identificados. $\mathrm{O}$ acompanhamento das atividades delegadas era contínuo, com fins de esclarecer ou sanar dúvidas.

Uma avaliação proporciona o feedback necessário à investigação da satisfação do consumidor e à maximização da valorização dos cuidados de saúde prestados.

\section{CONSIDERAÇÕES FINAIS}

Na conclusão do estudo verifica-se por meio da reação do idoso que as metas e objetivos foram alcançados. Ao implementar estratégias para melhorar a qualidade do cuidado, o enfermeiro também realiza novas investigações, amplia conhecimento com leituras, pesquisas, bem como elaboração de trabalhos que possam facilitar a excelência da assistência, em especial ao idoso sob sua responsabilidade.

Pode-se observar que o uso do diagnóstico de enfermagem na prática cotidiana tem sido atividade inovadora, embora, ainda, seja realizada experimentalmente em algumas instituições, por um grupo de profissionais. Poucos são aqueles que utilizam em suas instituições com participações e colaborações efetivas dos colegas. Esses, mesmo assim, relatam dificuldades, mas reconhecem a possibilidade de um cuidado colaborativo e inovador, revelados, essencialmente, pelos registros, evoluções de enfermagem, transformação do fazer diário e, principalmente, os 
Freitas MC, Mendes MMR.

\begin{tabular}{|c|c|}
\hline DIAGNÓSTICOS DE ENFERMAGEM & PRESCRIÇÕES DE ENFERMAGEM \\
\hline Déficit de volume de líquido & $\begin{array}{l}\text { - Estimular e registrar a hidratação oral } \\
\text { - Oferecer líquidos por via parenteral e enteral } \\
\text { - Registrar a hidratação parenteral, enteral e oral. } \\
\text { - Observar e anotar volume, densidade urinário. } \\
\text { - Pesar paciente pela manhã, diariamente. } \\
\text { - Observar evolução do edema em MSD e MMIl } \\
\text { - Monitoriza os valores seriados de Ht, Hb, sódio e potássio séricos. } \\
\text { - Monitorizar se o idoso tem evidência de volume excessivo de líquido decorrente da reposição rápida de líquido. }\end{array}$ \\
\hline $\begin{array}{l}\text { Risco para alteração da temperatura } \\
\text { corporal }\end{array}$ & $\begin{array}{l}\text { - Monitorizar temperatura corporal a cada } 4 \text { horas } \\
\text { - Manter ambiente aquecido (no caso de hipotermia), com uso de cobertores e aquecedores de ambiente. } \\
\text { - Manter ambiente ventilado (no caso de hipertermia), com janelas e portas abertas, roupa leve; } \\
\text { - Observar mudança no estado geral }\end{array}$ \\
\hline Integridade tissular prejudicada & $\begin{array}{l}\text { - Avalie e registre o momento e as circunstâncias da queimadura, assim como a extensão e profundidade. } \\
\text { - Observar e registrar a evolução das queimaduras durante a realização de banhos diários } \\
\text { - Fazer a limpeza das áreas queimadas durante o banho com técnica asséptica } \\
\text { - Realizar curativos acolchoados e com ataduras nas áreas queimadas } \\
\text { - controle da temperatura ambiente } \\
\text { - Monitorize e registre o tipo e a quantidade de drenagem dos ferimentos }\end{array}$ \\
\hline Distúrbio do padrão de sono & $\begin{array}{l}\text { - Estimular decúbito lateral esquerdo } \\
\text { - Usar travesseiros para apoio de MSE e tronco } \\
\text { - Observar queixas de dores } \\
\text { - Oferecer revistas e radio após refeição, antes de dormir. }\end{array}$ \\
\hline Mobilidade física prejudicada & $\begin{array}{l}\text { - Estimular e auxiliar na deambulação em ambiente reservado } \\
\text { - Proteger áreas sensíveis, pela queimadura, com curativos acolchoados. } \\
\text { - Estimular exercícios passivos com o MSD, mão D e dedos. } \\
\text { - Liberar a mudança de decúbito no leito, cadeira. }\end{array}$ \\
\hline $\begin{array}{l}\text { Estratégia ineficaz de resolução } \\
\text { individual }\end{array}$ & $\begin{array}{l}\text { - Autorizar a visita de familiares e da filha todos os dias, no período da tarde. } \\
\text { - Permitir que a filha ou familiares o acompanhasse, obedecendo ao Estatuto do idoso. }\end{array}$ \\
\hline Dor & $\begin{array}{l}\text { - Monitorize indicadores clínicos de dor } \\
\text { - Observar junto ao paciente os efeitos esperados das medicações para dor } \\
\text { - Promover ambiente confortável, no leito ou sentado. } \\
\text { - Administrar analgésico } \\
\text { - Fornecer explicações completas dos procedimentos de modo calmo. }\end{array}$ \\
\hline
\end{tabular}

\section{Quadro 4. Prescrições de enfermagem.}

resultados revelados por meio dos cuidados ao cliente.

No entanto, mediante as muitas dificuldades encontradas na implementação do processo de enfermagem no cotidiano da prática de enfermagem, faz-se necessário acreditar que tentativas deverão continuar acontecendo, mesmo que de maneira isolada. Estas possibilitarão, por meio de publicações, disseminar e estimular outros profissionais em diferentes instituições, pois a mesma permite avaliações criteriosas do fazer cotidiano, bem como proporciona aos enfermeiros fundamentos para as habilidades de pensamento crítico necessários ao exercício de uma maneria segura e eficiente.

Reconhece-se, portanto, que a utilização do processo de enfermagem é uma tentativa relevante de universalizar a linguagem entre a categoria, pois, provavelmente, irá possibilitar a excelência no cuidado cotidiano, em especial aos idosos que nos dias atuais se apresentam como parcela populacional que demanda atenção e estimula uma formação de profissionais para efetivar atenção.

\section{REFERÊNCIAS}

1. Hudak CM, Gallo BM. Cuidados intensivos de Enfermagem - uma abordagem holística. Rio de Janeiro (RJ): Guanabara Koogan; 1997.

2. Gomes DR, Serra MC, Pellon MA. Queimaduras. Rio de Janeiro (RJ): Revinter; 1995.

3. Alfaro-Lefevre R. Aplicação do processo de enfermagem: promoção do cuidado colaborativo. $5^{\mathrm{a}}$ ed. Porto Alegre (RS): Artmed; 2005.

4. Cruz CF. Diagnóstico de enfermagem e sua aplicação: revisão da literatura. Rev Esc Enf USP 1990 abr; 24(1): 149-62.

5. Ludke M, André MEDA. Pesquisa em educação: abordagens qualitativas. São Paulo (SP): EPU/EDUSP; 1986.

6. Berger LM, Mailloux-Poirier M. Pessoa idosa: uma abordagem global.
Lisboa (POR): Lusodidacta; 1995.

7. Bergamasco EC, Rossi LA, Carvalho EC, Dalri MCB. Diagnósticos de medo e ansiedade: validação de conteúdo para o paciente queimado. Rev Bras Enferm 2004 mar-abr; 57(2):170-7.

8. Lunney M. Pensamento Crítico e diagnósticos de enferma-gem: estudos de caso e análise. Porto Alegre (RS): Artmed, 2004.

9. Risner PB. Diagnosis: analysis and syntheseis of data. In: Christenses PJ, Kenney JW. Nursing Process: aplication of conceptual model. $3^{\text {rd }}$. St. Louis (LA): Mosby; 1986. p.124-67.

10. NANDA. Diagnóstico de Enfermagem da NANDA: definições e classificações - 2003-2004. Porto Alegre (RS): Artmed; 2005. 